\title{
A Way for Reducing Drug Supply Chain Cost for a Hospital District: A Case Study
}

\author{
Leonardo Postacchini ${ }^{1}$ (D), Filippo Emanuele Ciarapica ${ }^{2}$ (D), Maurizio Bevilacqua² ${ }^{(\mathbb{D}}$, \\ Giovanni Mazzuto ${ }^{2}$ (iD), Claudia Paciarottii \\ ${ }^{1}$ Libera Università di Bolzano, Faculty of Science and Technology (Italy) \\ ${ }^{2}$ Department of Industrial Engineering, Università Politecnica delle Marche (Italy)
}

Leonardo.Postacchini@natec.unibz.it,f.ciarapica@univpm.it,.m.bevilacqua@univpm.it,. g.mazsuto@univpm.it, c.paciarotti@,univpm.it

\section{Abstract:}

Purpose: This work aims at providing insights to optimise healthcare logistic of the drug management, in order to deal with the healthcare expenditure cut. In this paper the effects of different drug supply chain configurations, on the resulting average stock, service level and Bullwhip effect, of the studied supply chain, is quantitatively assessed.

Design/methodology/approach: A case study of an Italian district has been studied, taking into account three echelons: suppliers, central stock, and hospitals. A model of the various supply chain configurations has been created with the use of the simulation. Specifically, 24 supply chain configurations have been examined, stemming from the combination of several supply chain design parameters, namely: transshipment policies (Emergency Lateral Transshipment or Total Inventory Equalization); re-order and inventory management policies (Economic Order Quantity or Economic Order Interval); required service levels (90\% or 95\%); the number of available vans (one or two). For each configuration, hospital average stock, service level and a "Bullwhip effect" analysis are computed. To know which input variables are statistically significant, a DoE (Design of Experiments) analysis has been executed. 
Findings: The output of this paper provides useful insights and suggestions to optimize the healthcare logistic and drug supply chain. According to the developed DoE analysis, it can be stated that the introduction of transshipment policies provides important improvement in terms of service and stock levels. To reduce the Bullwhip effect, which results in a service level decreasing, and in a managing stock costs increasing, it is worth to adopt an EOQ re-order policy.

Practical implications: This research gives practical recommendations to the studied system, in order to reduce costs and maintain a very satisfactory service level.

Originality/value: This paper fulfils an identified need to study which combination of transshipment policies, re-order/inventory management policies and required service levels, can be the best one to reduce costs and maintain a very satisfactory service level, in the specific logistic system.

Keywords: healthcare logistic, drug management, supply chain design, discrete-events simulation model, design of experiments

\section{Introduction}

Drug management represents a large portion of the costs in the healthcare system, due to the significant costs of these products and their storage and control requirements. Reducing waste / increase the efficiency in healthcare system is therefore a global challenge, highlighting the need to identify any source of potential improvement and leverage on any tool, technique, methods and technologies to improve health care delivery and services (Bertolini, Bevilacqua, Ciarapica \& Giacchetta, 2011). Despite well-documented evidence of significant competitive advantage and cost reduction resulting from supply chain management (SCM) practices, the healthcare industry has been extremely slow to embrace these practices (Balaji, Lewis \& Rai, 2010; Lee, Lee \& Schniederjans, 2011); the challenges are many:

i. products and medical devices used procedures can be extremely expensive

ii. demand in terms of types and amount of product required for procedures can be highly unpredictable due to the diversity in patient characteristics

iii. inventory tracking can be difficult due to the urgency of medical procedures 
iv. product expiration and tracking issues caused by a lack of accountability for products managed under a consignment process (Balaji et al., 2010).

Chow and Heaver (1994) analysing the logistics activities stress that around $46 \%$ of an average hospital's operational budget is related to this type of activities; more precisely logistics costs may be split as follows: $27 \%$ for the cost of supplies, $4 \%$ for time spent by clinical staff on logistics tasks, and $15 \%$ for employees assigned to logistics duties, including material management, nutrition and laundry staff. More recent studies, analysis and report confirm that (i) the costs level of logistics activities remain very high (Ontario Buys \& Health Care Supply Network, 2007) but slightly lower than what is analysed by Chow and Heaver (1994) and (ii) the adoption of traditional supply chain methodologies / strategies is still in its earliest levels, despite can bring significant performance improvements (Gjerdrum, Jalisi, Papageorgiou \& Shah, 2000).

This paper examines the effects of different logistic solutions, on the performance of a specific healthcare supply chain. In particular, the case of an Italian district has been studied. Due to the cut in health expenditure, which has been implemented in the recent years by the central government, to all the hospitals present in each Italian district, it has been asked to reduce costs and inefficiencies in the logistic system. Many hospitals merged together in order to reduce inventories to manage, and also to achieve scale economies in the supply and transport stage of the drugs (Ciarapica, Giacchetta \& Paciarotti, 2008). According to Sinha and Kohnke (2009) there is a gap between the growing demand and available supply of high-quality, cost-effective, and timely health care, not only in developing and underdeveloped countries but also in developed countries. The significance of this problem is heightened when the economy is in recession. Recently, most healthcare organizations focus their attention on reducing the cost of their supply chain management (SCM) by improving the decision making pertaining processes' efficiencies (AbuKhousa, Al-Jaroodi, Lazarova-Molnar \& Mohamed, 2014). The availability of products through healthcare SCM is often a matter of life or death to the patient; therefore, trial and error approaches are not an option in this environment. Simulation and modeling (SM) has been presented as an alternative approach for supply chain managers in healthcare organizations to test solutions and to support decision making processes associated with various SCM problems.

In this context this work aims at providing insights to optimise healthcare logistic of the studied system, in order to deal with the Italian health expenditure cut. We consider the following design parameters: transhipment policy, re-order and inventory management policies, the service level and the number of available transshipment vans. The analysis is based on a discrete-event simulation model, reproducing a specific healthcare supply chain, and on the computation of inventory and of the demand variance amplification for the supply chain configurations examined. A subsequent Design of Experiment (DoE) analysis is 
performed to identify and quantify single and combined effects of the above parameters on the results observed: average stock, service level and Bullwhip effect.

The paper has been organized as follows. The next section reviews the relevant literature concerning supply chain simulation studies and lateral transshipment policies, with particular attention to works focusing on supply chain design and optimization. The Section 3 describes the simulation model that has been developed to reproduce the drugs supply chain. The key results of the simulation are detailed in Section 4. Section 5 discusses the results of the simulations, and Section 6 proposes concluding remarks about the study.

\section{Literature Analysis}

Today's business literature is rife with supply chain management models, theories, and more importantly, stories of successful application of SCM principles in health care supply chain. For example, thanks to the performance achieved by the new auto-id technologies, such as radio frequency identification (Sarac, Absi \& Dauzère-Pérès, 2010), it is possible to trace and track drugs in order to obtain significantly improvement in the visibility and security of the healthcare supply chain (Koh, Schuster, Chackrabarti \& Bellman, 2003; Bevilacqua, Ciarapica, Mazzuto \& Paciarotti, 2013). In addition to this, Harrison and Tatsuya (2006) proposed the use of electronic pedigrees, mass serialisation and authentication of the drug to combat counterfeit drug problems. While none of these prior studies considered the healthcare supply chain of a specific drug with unique product features, Bishara (2006) assessed the risks involved in shipping, handling, storage and distribution of biopharmaceuticals sensitive to temperature fluctuations. An efficient, user-friendly supply chain can also impact the hospital's revenues by engendering physician loyalty and staff retention and providing better customer service (Haavik, 2000). Despite the recognized importance of managing the hospital supply chain, tremendous variability exists in design and management of supply chains / distribution of drugs (Bevilacqua, Ciarapica \& Paciarotti, 2009; Rossetti, Handfield \& Dooley, 2010). There has also been limited academic research that helps to design a successful implementation SCM program or to recommend best practices (Ivan-Su, Gammelgaard \& Yang, 2011). A healthcare logistic design is a complex issue due to assorted sources of drug, high number of drug manufacturers and multiple layers of drug distribution channels.

Healthcare supply chain management (HSCM) using Discrete Event Simulation (DES) has received in literature considerable attention for more than two decades. Despite the widespread literature on this topic, efforts to re-engineering drug supply chain in the hospitals are very limited. Several studies (Naseer, Eldabi, Jahangirian, \& Stergioulas, 2008; Katsaliaki \& Mustafee, 2011) explored the value of DES to support decision making in healthcare SCM as in other industries. More studies developed SM tools to tackle problems in healthcare SCM. For example, Lapierre and Ruiz (2007) addressed the problem of logistics and inventory 
replenishment through coordinating the procurement and distribution operations while respecting inventory capacities. Haijema, van der Wal and van Dijk (2007) and Kopach, Balcioğlu and Carter (2008) dealt with the optimization problem of production and inventory management of blood supplies. Jacobson, Sewell, Proano and Jokela (2006) captured the relationship between vaccine supply and vaccine demand to calculate pediatric vaccine stock levels necessary for avoiding interruptions in vaccination schedules for children. Ana, Ivy and King (2008) determined the optimal inventory policies for an inpatient hospital pharmacy with enhancement in cost performance. Lastly, Rytilä and Spens (2006) developed a DES tool to analyze the supply chain of blood and blood products. They found that decision makers can use the knowledge created by DES to make better and less risky decisions regarding changes in SC. They concluded that DES can aid in increasing the overall quality of healthcare by allowing better allocation of scarce resources.

Regarding the output analyzed in literature about HSCM using DES, Behzad, Moraga and Chen (2011) studied bullwhip effect in healthcare supply chain. The research goal of this paper was to model and simulate the internal service supply chains of a healthcare system to study the effects of different parameters on the outputs and capability measures of the processes. Behzad et al. (2011) specific objectives were to analyse medication delivery errors in a community hospital based on the results of the models and to explore the presence of bullwhip effect in the internal service supply chains of the hospital. Chan and Chan (2005) use simulation for building and testing five different supply chain models. Their main aim is to determine which supply chain models could achieve the optimal performance, in terms of inventory level, order lead time, resources utilization, and transportation costs.

Numerous strategies for archiving optimal performance of logistic system have been proposed and investigated in both practice and academic over the past decades. In this work we focused our attention on a strategy, commonly practiced in multi-location supply chain systems facing stochastic demand, allows movement of stock between locations at the same echelon level or even across different levels. These stock movements are termed lateral transshipments, or simply, transshipments (Chiou, 2008). As the literature and practice suggested, there are two classes of transshipment. Lee, Jung and Jeon (2007) proposed that lateral transshipment can be divided into two categories: emergency lateral transshipment (ELT) and preventive lateral transshipment (PLT). ELT directs emergency redistribution from a retailer with ample stock to a retailer that has reached stockout. However, PLT reduces risk by redistributing stock between retailers that anticipate stockout before the realization of customer demands. In short, ELT responds to stockout while PLT reduces the risk of future stockout. This concept of transshipment classification is similar to (Banerjee, Burton \& Banerjee, 2003), wherein two kinds of policies were proposed: Lateral transshipment based on availability (TBA) and Lateral transshipment for inventory equalization (TIE). TBA transships stock to retailers with less than desirable levels until all stock is depleted. However, this policy is problematic when desired stock levels are determined incorrectly. TIE redistributes stock to match the target level of 
demand of each retailer whenever there are retailers with less than desirable stock levels. This policy does not respond to stockout after redistribution, because redistribution is performed once in every replenishment cycle.

\section{Case Study}

In this work a case study of an Italian healthcare supply chain has been analysed. Three echelons have been considered, starting from the drug suppliers, followed by a central warehouse (distribution centre), and finally by the three hospitals of the studied Italian district (called "Civitanova Marche", "Macerata" and "Camerino") (see Figure 1). These are small/medium size hospitals with 300/400 sleeping accommodations. The distance between these hospitals vary from minimum value of $30 \mathrm{~km}$ to a maximum value of $60 \mathrm{~km}$.

In the As-Is configuration, no Lateral Transshipment policies are applied, and so no drug exchange is allowed on the same echelon. To manage the orders, a periodic review policy (EOI, Economic Order Interval) or a reorder point policy (EOQ, Economic Order Quantity) are applied, submitting the order to the upper echelon (in this case the central warehouse).

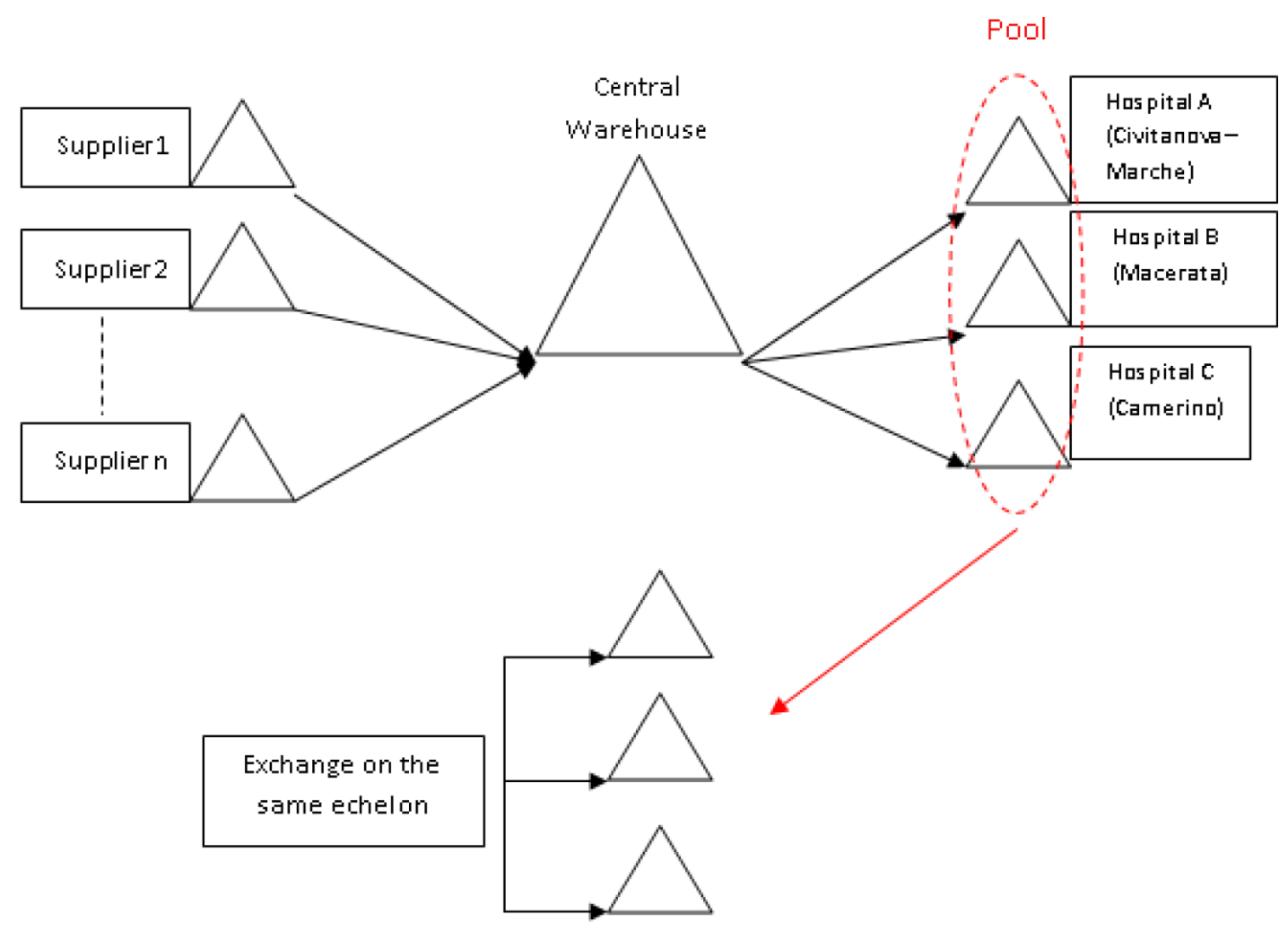

Figure 1. Supply Chain Structure 
In the developed simulation models, the stocks of the suppliers have been considered as unlimited, whereas the same inventory management policy has been applied to both the central warehouse echelon and the hospitals echelon. Moreover, for each echelon, a procurement lead time $(L)$ has been introduced, which includes the required time for transport, order and warehouse activities. In the To-Be configuration models, the lateral transshipment policy has been introduced on the third echelon (the hospitals echelon), in order to evaluate its effect on service and stock levels. The simulation software Arena, which is particularly proper for this kind of problems, has been used in this study. Due to the large number of variables to take into account, and quite complex model logic, great part of the model has been programmed with the use of VBA (Visual Basic for Application).

In this work, according to hospital needs, three output of the simulation models (dependent variables) have been considered:

- Average stock level of the three hospital;

- Achieved Service Level for the hospitals;

- Demand variance amplification for the supply chain: Bullwhip effect (Bullwhip effect, defined as the ratio between variance of orders received by echelon $\mathrm{N}$ and the variance of final customer's demand, i.e. $\sigma 2 \mathrm{~N} / \sigma 2$ ).

\subsection{Supply Chain Configurations}

Due to the very limited hospitals budget many solutions for optimizing drug supply chain have not been taken into consideration. For instance solutions that involved a design and a realization of a centralized warehouse have been discarded because of high fulfillment costs. In this context only four independent variables have been taken into consideration:

1. Lateral Transshipment policy (see section 3.1.1):

- Emergency Lateral Transshipment (ELT)

- When the stock is below the Safety Stock $(<\mathrm{SS})$

- When the stock is in stock out $(<0)$

- Total Inventory Equalization (TIE):

- At $1 / 3$ of time between two orders to the central warehouse $(1 / 3)$

- At $2 / 3$ of time between two orders to the central warehouse $(2 / 3)$ 
2. Re-order policy (see section 3.1.2):

- Economic Order Quantity (EOQ)

- Economic Order Interval (EOI)

3. Required Service Level (by the hospitals). We considered two values: $90 \%$ and $95 \%$

4. Number of vans, used for the Lateral Transshipment. We considered 1 or 2 vans because of the constraints in hospitals budget.

In order to simplify the model, the following assumptions have been formulated:

- It has been chosen to develop a demand with a stochastic component, considering hospital drugs that belong to the classes $A$ and $B$ per value (Drug value $=$ amount consumed (per year) - price) ( $A B C$ analysis). The demand function has been obtained, by analyzing aggregated historical data for those particular drugs, of the three hospitals. In particular, it has been noticed that the Beta Distribution was the best function to approximate the historical demand variability (minimum Square Error). So, in this model, the Beta Distribution has been chosen to simulate the daily demand and its variance.

- Each hospital uses the same re-order and transshipment policy;

- Initial Stock Level and Cost of every item has been assumed equal to the value recorded by hospitals at the last day of 2013 .

- The ordering cost is estimated as the sum of average buyer time multiplied by employee hour cost and fixed transportation cost. This value has been assessed equal to $€ 35$ per order.

- Annual holding rate of the product in stock is estimated as a percentage of the cost of a product and is the sum of cost of capital (WACC) and occupancy cost. This value has been assessed equal to $9 \%$.

The rules for ordering and transshipment policies between hospitals have been explained in section 3.1.1 and 3.1.2. 


\subsubsection{Lateral Transshipment Policy}

Two different policies of lateral transshipment have been evaluated:

1. Lateral Transshipments based on Availability (TBA) policy (Banerjee et al., 2003): in literature it is often named as Emergency Lateral Transshipment (ELT). In this case, at time $t$, it is checked if one or more warehouses are in stock shortage. When it is so, $S h_{j}(t), \forall j$ and $A_{k}(t), \forall k$ are evaluated:

$$
S h_{j}(t)=D_{j}-I_{j}(t)
$$

Defining:

$S h_{j}(t)$ : Shortage of the hospital $j$ at time $t$

$D_{j}$ : Expected Daily Demand Rate for the hospital $j$

$I_{j}(t)$ : Available Inventory in the hospital $j$ at time $t$

$$
A_{k}(t)=I_{k}(t)-E\left[I_{k}(t)\right], k=1,2, \ldots, K
$$

Defining:

$A_{k}(t)$ : Available Amount for LT of the hospital $k$ at time $t$

$I_{k}(t)$ : Available Inventory in the hospital $k$ at time $t$

$E\left[I_{k}(t)\right]:$ Expected Stock Level of the hospital $k$ at time $t$

$K$ : Number of hospitals where $I_{k}(t)>E\left[I_{k}(t)\right]$

$$
E\left[I_{k}(t)\right]=D_{i} \cdot\left(\tau_{t, R}-t+L\right)
$$

Defining:

$\tau_{t, R}:$ Scheduled time of receipt of the next shipment from the supplier at the higher echelon (deterministically known)

\section{L: Procurement Lead Time}

To sum up, the stock level of each hospital is monitored, and when it descends below the Lateral Transshipment point (LT), that is the threshold value for activating the transshipment process, the following procedure is applied:

- The $K$ - hospitals, that have a surplus of a particular drug, are ranked on their drug surplus quantity, in a descended order, and labeled with [1], [2], ..., $[K]$, so that $A_{[1]}(t) \geq A_{[2]}(t) \geq \ldots \geq A_{[K]}(t)$. The same kind of ranking is done for 
the hospitals that have a shortage of that particular drug, so that $S H_{[1]}(t) \geq S H_{[2]}$ $(t) \geq \ldots \geq S H_{[]}(t)$.

- The lateral transshipment is executed between the hospital with the surplus $A_{[1]}$ $(t)$ and the hospital with the shortage $S H_{[1]}(t)$. The quantity of this transshipment is $Q_{[1],[1]}$, and it is evaluates using $Q_{[1],[1]}=\operatorname{minimum}\left\{A_{[1]}(t), S H_{[1]}\right.$ $(t)\}$

- The stock levels are updated, and the whole procedure is repeated until $A_{[1]}(t) \cdot S H_{[1]}$ $(t)=0$.

This implies that either all current transshipment needs have been met, or the total available transshipment quantity among all the excess hospitals has been exhausted. Note that with this policy in effect, the set of lateral shipment decisions, described above, may have to be made more than once during a review cycle, based on the transshipment order point signal. Furthermore, if a transshipment need is indicated 1 day prior to time $\tau_{t, R}$, the arrival time of the next cycle's shipment from the upper echelon, no lateral shipments are made in the current cycle, due to the anticipated delivery of a relative large quantity the following day.

2. Lateral Transshipment for Inventory Equalization (TIE) policy: in this case, as opposed to the TBA policy described above, inventory redistribution (i.e. a set of lateral shipments) occurs no more than once in every review cycle. At time $t$, within a review period, inventories are checked, and then the drug is redistributed among the hospitals, such that each of them will have an equal number of days' supply.

Let $\operatorname{El}_{i}(t)$ represent the equalized inventory level at location $i$, after redistribution, determined at time $t$.

It follows that:

$$
E I_{i}(t)=\frac{D_{i}}{\sum_{i=1}^{N} D_{i}} \cdot\left[\sum_{i=1}^{N} I_{i}(t)\right]
$$

Defining:

$E I_{i}(t)$ : Equalized Inventory of the hospital $i$ at time $t$

$D_{i}$ : Expected Daily Demand Rate for hospital $i$

$I_{i}(t)$ : Available Inventory of the hospital $i$ at time $t$

$N$ : Number of hospitals 
Thus, for any hospital $j$, if $E I_{i}(t)-I_{j}(t)>0, j=1,2, \ldots, j$ the left value of this inequality is the amount that needs to be shipped into this hospital for achieving inventory equalization. By the same token, for any other location $k$, if $I_{k}(t)-E i_{k}(t)>0, k=1,2$, $\ldots, K$ the left value in this inequality is the amount available for shipping out of this hospital. It has been assumed that the redistribution of stock, for achieving inventory equalization, occurs through a complete tour of a single transport vehicle, which visits each of the $K$ source hospital exactly once for stock pick-up, and each of the $J$ destination hospital exactly once for stock delivery, representing an embedded special version of the travelling salesman problem.

\subsubsection{Re-order Policy}

Two re-order policies have been considered in this work (Chiou, 2008):

1. Inventory Control Policy $(Q, R)$ : the $(Q, R)$ policy, with a continuous checking of the inventory, considers a fixed quantity $Q$ (Economic Order Quantity, EOQ) to be ordered, and a re-order point $R$. This quantity $Q$ is ordered when the stock level goes down the re-order point $R$.

$$
E O Q=\sqrt{\frac{2 \cdot C_{0} \cdot D}{C_{C}}}
$$

$D$ : Annual demand

$C_{0}:$ Cost to launch an order

Q: Economic Order Quantity (EOQ)

$C_{C}$ : Cost of stocking

$C c=$ Product cost $\cdot$ Annual holding rate of the product in stock

The Re-order point $R$ :

$$
R=S S+\bar{D} \cdot \overline{L T}
$$

$R$ : Re-order point

SS: Safety Stock

$\bar{D}$ : Average daily demand

$\overline{L T}$ : Average Lead Time 
The safety stock is calculated considering the service level that has been chosen to be guaranteed:

$$
S S=Z \cdot \sqrt{\overline{L T} \cdot \sigma_{D}^{2}+\bar{D}^{2} \cdot \sigma_{L T}^{2}}
$$

Defining:

SS: Safety stock
Z: Z-score
$\sigma_{D}:$ Standard deviation of demand
$\sigma_{L T}:$ Standard deviation of Lead Time

2. Economic Order Interval: with this policy, an order is launched at a fixed time. The order quantity is given by the difference between the Order Up To Level and the quantity of product stocked in the warehouse. The EOI model fixes as constant the time period between two following orders, operating with a periodic checking on stock levels, and an order quantity which is variable in time. This model determines the time period between two orders that minimizes the annual management cost.

The Order up to level, that is the maximum stock level, is given by:

$$
E=\bar{D} \cdot(E O I+L T)+S S
$$

E: Order up to level

SS: Safety stock

$\bar{D}$ : Average daily demand

$L T$ : Procurement Lead Time

EOI: Economic Order Interval

The constant re-order interval $(T)$ is:

$$
T=E O I=\sqrt{\frac{2 \cdot C_{0}}{D \cdot C_{C}}}
$$

So, every $T$ days, an order will be launched $\left(Q_{o r d}\right)$, with a quantity given by:

$$
Q_{\text {ord }}=E-Q_{\text {att }}
$$

Qord: Quantity $Q$ to be ordered at time $T$

E: Maximum stock capacity of the warehouse

$Q_{\text {att: }}$ Quantity of stock, available at time $T$ in the warehouse. 


\section{Results}

In order to obtain statistically significant results, it has been decided to run each simulation for 15 times; this value allowed the simulation to reach stable outputs for three echelons.

Regarding the possible combination number of the independent variables, it has been chosen to use more than a single factorial plan in the Design of Experiment analysis (Montgomery, 2008), in order to manage and visualize better the relationships among the various variables. For this study, it has been chosen to adopt three factorial plans, for a total of 24 supply chain configurations, which are the most relevant obtainable supply chain configurations. According to one of the aims of this paper, in this first analysed factorial plan (principal), it has been evaluated the effect of different Lateral Transshipment policies, in combination with different re-order policy and number of vans (Figure 2).

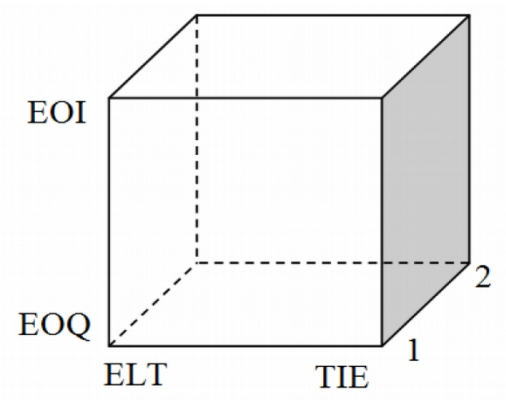

Figure 2. DoE: Principal factorial plan

Two other factorial plans (sub-plans) have been created, one for the Emergency Lateral Transshipment (Figure 3), and one for the Total Inventory Equalization (Figure 4):

\section{- ELT}

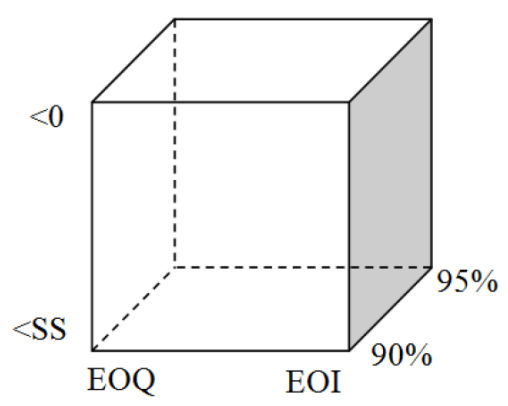

Figure 3. DoE: Factorial sub-plan ELT 
- $\quad$ TIE

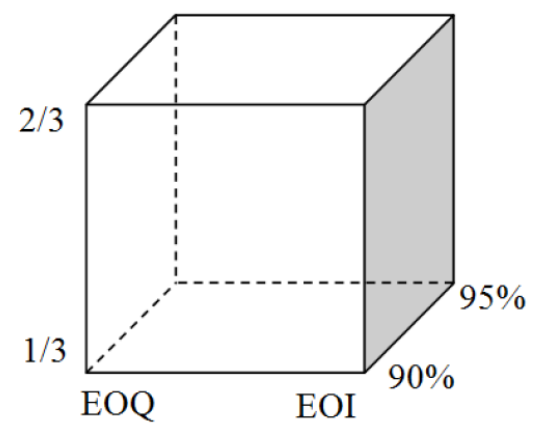

Figure 4. DoE: Factorial sub-plan TIE

The Table 1 shows the results of the simulations:

\begin{tabular}{|c|c|c|c|c|}
\hline & \multicolumn{2}{|c|}{ Scenarios } & \multirow{2}{*}{$\begin{array}{r}\text { Average Stock (x 1000€) } \\
2,480\end{array}$} & \multirow{2}{*}{$\begin{array}{r}\text { Average Service Level } \\
99.60 \%\end{array}$} \\
\hline \multirow{8}{*}{$\begin{array}{l}\text { Principal Factorial } \\
\text { plan }\end{array}$} & ELT-EOQ-1 & $(1)$ & & \\
\hline & TIE-EOQ-1 & $a$ & 3,260 & $99.82 \%$ \\
\hline & ELT-EOI-1 & $b$ & 4,860 & $100.00 \%$ \\
\hline & TIE-EOI-1 & $a b$ & 5,260 & $100.00 \%$ \\
\hline & ELT-EOQ-2 & c & 2,480 & $99.61 \%$ \\
\hline & TIE-EOQ-2 & ac & 3,260 & $99.82 \%$ \\
\hline & ELT-EOI-2 & bc & 4,860 & $100.00 \%$ \\
\hline & TIE-EOI-2 & $a b c$ & 5,260 & $100.00 \%$ \\
\hline \multirow{8}{*}{$\begin{array}{l}\text { Factorial sub-plan } \\
\text { ELT }\end{array}$} & EOQ_SS_90 & $(1)$ & 2,710 & $99.85 \%$ \\
\hline & EOI_SS_90 & $a$ & 4,860 & $100.00 \%$ \\
\hline & EOQ_0_90 & $b$ & 2,480 & $99.61 \%$ \\
\hline & EOI_0_90 & $a b$ & 4,880 & $100.00 \%$ \\
\hline & EOQ_SS_95 & c & 2,910 & $99.91 \%$ \\
\hline & EOI_SS_95 & ac & 4,870 & $100.00 \%$ \\
\hline & EOQ_0_95 & $\mathrm{bc}$ & 2,650 & $99.42 \%$ \\
\hline & EOI_0_95 & $a b c$ & 4,880 & $100.00 \%$ \\
\hline \multirow{8}{*}{$\begin{array}{l}\text { Factorial sub-plan } \\
\text { TIE }\end{array}$} & EOQ-1/3-90 & $(1)$ & 3,260 & $99.82 \%$ \\
\hline & EOI-1/3-90 & a & 5,260 & $100.00 \%$ \\
\hline & EOQ-2/3-90 & $b$ & 3,100 & $99.85 \%$ \\
\hline & EOI-2/3-90 & $a b$ & 4,940 & $100.00 \%$ \\
\hline & EOQ-1/3-95 & c & 3,380 & $99.85 \%$ \\
\hline & EOI-1/3-95 & $\mathrm{ac}$ & 5,260 & $100.00 \%$ \\
\hline & EOQ-2/3-95 & bc & 3,270 & $99.82 \%$ \\
\hline & EOI-2/3-95 & $a b c$ & 4,940 & $100.00 \%$ \\
\hline
\end{tabular}

Table 1. Results of simulations 
Applying the DoE analysis on these data, it is possible to understand which input variables have the major effect on the output. The Table 2 shows the results of the DoE analysis:

\begin{tabular}{|c|c|c|c|c|c|}
\hline & & \multicolumn{2}{|c|}{ Average Stock } & \multicolumn{2}{|c|}{ Service Level } \\
\hline & & Fo & $\mathbf{P}$ & $\mathbf{F O}$ & $\mathbf{P}$ \\
\hline \multirow{7}{*}{$\begin{array}{c}\text { Principal Factorial } \\
\text { plan }\end{array}$} & $\mathbf{A}$ & 5693.02 & 7.31E-98 & 10.58809 & 0.001505 \\
\hline & $\mathbf{B}$ & 78058.44 & $4.20 \mathrm{E}-161$ & 72.19558 & $9.43 \mathrm{E}-14$ \\
\hline & $\mathbf{A B}$ & 567.0763 & $1.21 \mathrm{E}-45$ & 10.34574 & 0.001697 \\
\hline & C & 0.002142 & 0.963172 & 0.005244 & 0.942402 \\
\hline & $A C$ & 0.002142 & 0.963172 & 0.005244 & 0.942402 \\
\hline & BC & 0.002142 & 0.963172 & 0.005244 & 0.942402 \\
\hline & $\mathrm{ABC}$ & 0.002142 & 0.963172 & 0.005244 & 0.942402 \\
\hline \multirow{7}{*}{$\begin{array}{l}\text { Factorial sub-plan } \\
\text { ELT }\end{array}$} & $\mathbf{A}$ & 83540.02 & $9.40 \mathrm{E}-163$ & 39.5388 & $6.38 \mathrm{E}-09$ \\
\hline & B & 236.8341 & $2.13 E-29$ & 14.8337 & 0.0002 \\
\hline & $\mathbf{A B}$ & 280.9652 & $2.63 E-32$ & 6.5802 & 0.0116 \\
\hline & C & 162.3584 & $1.58 \mathrm{E}-23$ & 0.4123 & 0.5221 \\
\hline & AC & 133.6443 & $8.02 \mathrm{E}-21$ & 0.4123 & 0.5221 \\
\hline & BC & 3.1981 & 0.0764 & 1.6221 & 0.2054 \\
\hline & $\mathrm{ABC}$ & 0.3645 & 0.5472 & 1.6221 & 0.2054 \\
\hline \multirow{7}{*}{$\begin{array}{l}\text { Factorial sub-plan } \\
\text { TIE }\end{array}$} & $\mathbf{A}$ & 38819.27 & $3.80 \mathrm{E}-144$ & 36.42141 & $2.10 \mathrm{E}-08$ \\
\hline & B & 596.9407 & $1.08 \mathrm{E}-46$ & 0.000934 & 0.975671 \\
\hline & $\mathbf{A B}$ & 99.00885 & $4.28 \mathrm{E}-17$ & 0.000807 & 0.977385 \\
\hline & C & 61.12435 & $3.19 \mathrm{E}-12$ & 0.000941 & 0.975584 \\
\hline & AC & 61.12435 & $3.19 \mathrm{E}-12$ & 0.000941 & 0.975584 \\
\hline & BC & 1.285235 & 0.259349 & 0.292899 & 0.589443 \\
\hline & $A B C$ & 1.285235 & 0.259349 & 0.292899 & 0.589443 \\
\hline
\end{tabular}

Table 2. Results of the DoE analysis

\subsection{Bullwhip Effect}

In order to assess the Bullwhip effect on the last two echelons, another factorial plan has been created and analyzed (Figure 5). This time with two variables that showed to be significant in the previous analysis (see section 4): re-order policy (EOQ-EOI) and lateral transshipment policy (ELT-TIE).

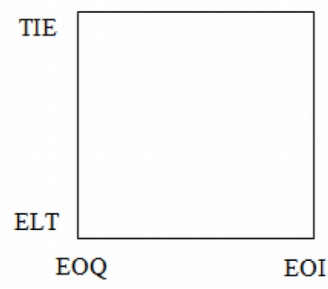

Figure 5. Factorial plan: Bullwhip effect 
ELT policy has been set with the assumption "stock < Safety Stock" (see par. 3.1), whereas TIE policy has been set with the assumption "at $2 / 3$ of time between two orders to the central warehouse" (see par. 3.1)

The Table 3 shows the results of the Bullwhip effect analysis:

\begin{tabular}{|l|r|r|r|r|}
\cline { 2 - 5 } \multicolumn{1}{c|}{} & \multicolumn{1}{|c|}{$\begin{array}{c}\text { EOQ-ELT } \\
(\mathbf{1})\end{array}$} & $\begin{array}{c}\text { EOI-ELT } \\
(\mathbf{a})\end{array}$ & \multicolumn{1}{c|}{$\begin{array}{c}\text { EOQ-TIE } \\
\text { (b) }\end{array}$} & $\begin{array}{c}\text { EOI-TIE } \\
\text { (ab) }\end{array}$ \\
\hline Average variance of the central warehouse demand $\left(\sigma^{2}\right)$ & 249682.53 & 588447.19 & 283246.93 & 495535.89 \\
\hline Average variance of the final demand $\left(\sigma^{2}\right)$ & 17563.45 & 17002.28 & 18548.06 & 15241.51 \\
\hline Bullwhip effect & 14.2160 & 34.6099 & 15.2710 & 32.5123 \\
\hline
\end{tabular}

Table 3. Results of the Bullwhip effect analysis

Applying the DoE analysis on these data, it is possible to understand which input variables have the major effect on the output result (Table 4).

\begin{tabular}{|c|r|r|}
\cline { 2 - 3 } \multicolumn{1}{c|}{} & \multicolumn{1}{c|}{ FO } & \multicolumn{1}{c|}{ P } \\
\hline A (EOQ-EOI) & 1319.9602 & $1.27 \mathrm{E}-40$ \\
\hline B (ELT-TIE) & 0.0003 & 0.987398 \\
\hline AB & 4.8578 & 0.031649 \\
\hline
\end{tabular}

Table 4. DoE analysis - Bullwhip effect

\section{Discussion}

Knowing now which are the variables that have the most influence on each factorial plan, it is possible to represent each factorial plan, in a diagram and analyze the output.

\subsection{Principal Factorial Plan}

The analysis of the results shows a substantial difference, in terms of average stock and service level, in the use of an Economic Order Quantity, or an Economic Order Interval policy (Figure 6). The average stock on EOQ policy are almost half of the EOI inventory policy. This result was expected through the DoE analysis, since the value of $P$ appears to be much smaller than the other values (4.2E-161). In all the simulation, the average stock of the Emergency Lateral Transshipment (ELT) policy is lower than the Total Inventory Equalization (TIE) policy. The influence of the transshipment policy is lower in an EOI re-order policy, rather than in an 
EOQ. The service level depends mainly on the applied re-order policy, with a value of $P=9.43$ E-14, that is much smaller for the $B$ factor (re-order policy) than for the $A$ factor (transshipment policy, with $P=0.001505)$. Despite this large difference, the influence of the $A$ factor is statistically significant $(P<0.005)$. The number of vans has a negligible influence, with a value of $P=0.942402$. If the priority is to decrease costs and thus to decrease the level of stocks, it is worth to apply the EOQ re-order policy jointly with an ELT transshipment policy.

If the priority is to increase the service level, the DoE analysis showed that, only the re-order policy is the statistically significant parameter for this purpose $(\mathrm{P}=2.1 \mathrm{E}-08)$, and that the EOI policy has to be preferred. In this case, the choice of EOI policy carries to a raising in holding cost, for a small increase in the service level.

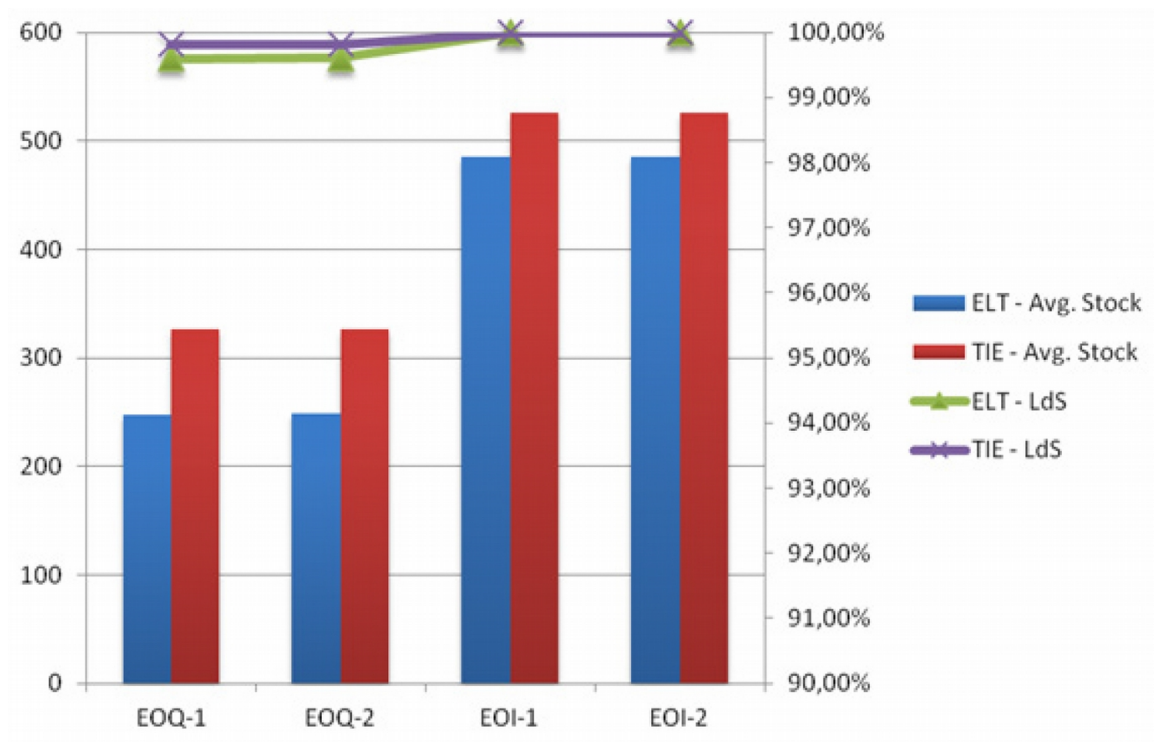

Figure 6. Principal factorial plan

(LdS = Service Level; Avg. Stock = Average stock of the three hospitals)

\subsection{Factorial sub-plan - ELT}

As mentioned before, also in this factorial plan it is possible to note a substantial difference between the average stock level under the EOQ policy, or the EOI policy (Figure 7). Even the other variables, such as launching the transshipment order under the safety stock level, or in the stockout situation, or as the calculation of safety stock considering a service level of $90 \%-95 \%$, are statistically significant for the stock levels ( $P=2.13 \mathrm{E}-29 ; \mathrm{P}=1.58 \mathrm{E}-23)$. As expected, the average stock level is higher in the case the transshipment order has been launched under the safety stock level, and, at the same time, the service level has been increased $(P=0.0002)$, than the remaining situations. 


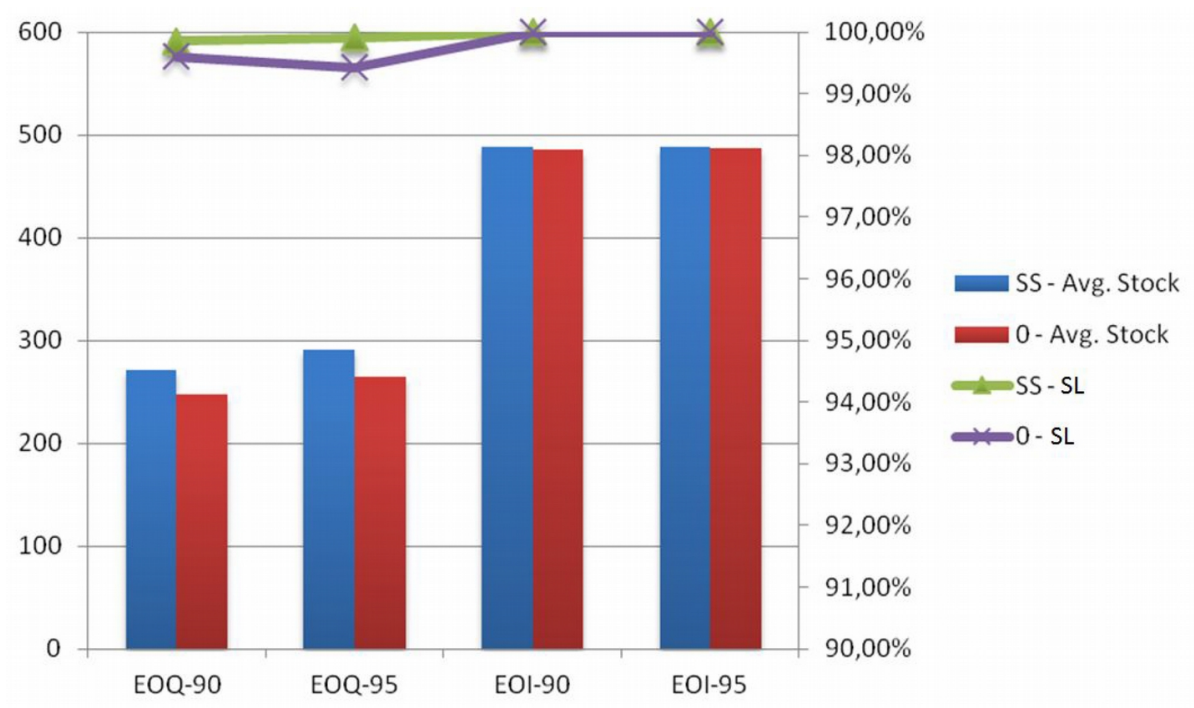

Figure 7. Factorial sub-plan -

ELT (LdS = Service Level; Avg. Stock = Average stock of the three hospitals)

In order to reach a service level of $95 \%$, under a EOQ policy, the average stock level increases $(P=1.58 \mathrm{E}-23)$. With the EOI policy, the stock level difference between the $90 \%$ and $95 \%$ of service level, becomes negligible.

\subsection{Factorial Sub-Plan - TIE}

As result of the DoE analysis on this factorial plan, Figure 8 shows that the service level does not depend on "when" the levels of the warehouse are balanced $(P=0.975671)$. The only parameter that has an influence on service level, is the applied re-order policy $(P=2.1 \mathrm{E}-08)$.

All input parameters are statistically significant for the average stock, with a value of $P=3.8$ $\mathrm{E}-144$ for the re-order policy, a value of $\mathrm{P}=1.08 \mathrm{E}-46$ for the balancing moment, and a value of $P=3.19 \mathrm{E}-12$ for the calculation of safety stock. The most important event to note here is the difference between the balancing of the warehouse levels at $1 / 3$ of the interval rather than $2 / 3$. Balancing at $1 / 3$, the average stock is slightly higher than balancing at $2 / 3$. As mentioned before, this small increase in the average stock does not have a statistically significant influence on the service level. 


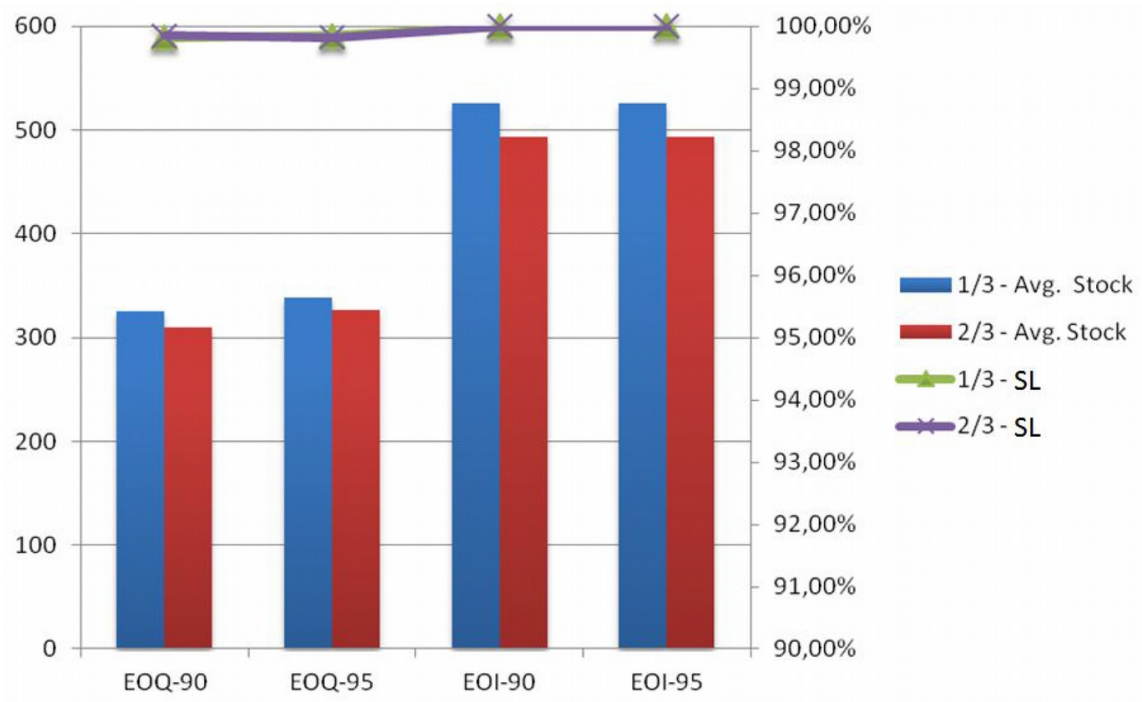

Figure 8. Factorial sub-plan -

TIE (LdS = Service Level; Avg. Stock = Average stock of the three hospitals $)$

\subsection{Bullwhip Effect}

From the diagram of Figure 9, and the performed DoE analysis, it can be stated that the transshipment policy, applied at the final echelon (i.e. the level of hospitals), has no statistically significant influence $(P=0.987398)$ on Bullwhip effect, in this system. Only the re-order policy (EOQ-EOI), which is applied on both the level of the central warehouse and the level of hospitals, generates the bullwhip effect $(P=1.27 \mathrm{E}-40)$.

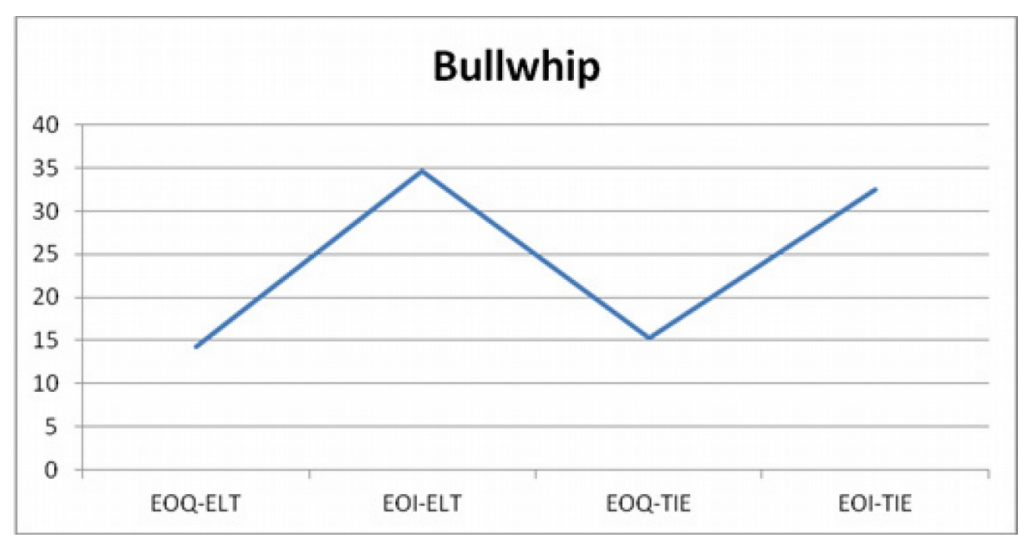

Figure 9. Bullwhip effect 


\section{Conclusion}

Based on a discrete-event simulation model, reproducing a drug supply chain of a healthcare system, a quantitative assessment of the effects of different supply chain configurations on the inventory levels, and bullwhip effect, has been provided, in the observed system.

In the As-Is supply chain configuration the three hospitals, analysed in this work, have an average service level, for the drug taken into consideration, equal to $96.1 \%$ and an average stock level equal to 5,630 (x1000€). To-Be models covers 24 new possible supply chain configurations, resulting from the combination of several design parameters. For each scenario, supply chain performances have been computed, starting from simulation outcomes and several input parameters available in literature. Moreover, a statistical effect analysis has been performed, in order to identify possible significant impact of single/combined supply chain design parameters, on the resulting inventory and demand variance amplification. According to the developed $D o E$ analysis, it can be stated that the introduction of transshipment policies provides important improvement in terms of service and stock levels. All new supply chain configurations taken into considerations show a decreasing in average stocks and an increasing in service level.

The variable that affects the most, on the average stock and on the service level, is the reorder policy. The EOQ policy is the more suitable in order to minimize the average stock level. If the service level is the primary benchmark, the EOI policy has to be preferred. The latter has been resulted to have a very significant increase in the average stock level, with a small increase in the service level. In general, the service level keeps very high (from $98 \%$ to up), and this makes more likely the chosen policies will be based on the level of the average stock.

The number of vans is a negligible variable. In this case, one single van is enough to carry out the various transshipment activities. Between the two transshipment policies, ELT and TIE, it is preferable to choose the first one. This policy requires a low average stock level, and so it further minimizes the holding costs. Choosing the ELT policy, it is worth to launch a transshipment order when the stock goes in stock-out. Choosing the TIE policy, it is worth to use it with the inventory level balancing at $2 / 3$ the time between two orders to central warehouse, in order to reduce the average stock. To reduce the Bullwhip effect, which results in a service level decreasing, and in a managing stock costs increasing, it is worth to adopt an EOQ re-order policy.

In conclusion, according to hospitals needs to reduce costs and maintain a very satisfactory service level, this configuration has been chosen: Emergency Lateral Transshipment (Transshipment policy), stock is in "stockout" $(<0)$ (Transshipment execution), EOQ (Re-order policy), 1 (Number of vans), $90 \%$ (Service level value for the calculation of the safety stock). This supply chain configuration allowed the hospitals to reduce the holding costs. The annual holding cost was estimated as a percentage of the cost of the drugs. Considering an annual 
holding rate of the product in stock equal to $9 \%$ and an average stock reduction equal to $56 \%$ $(3,150 \times 1000 €=5,630-2,480)$ the hospitals may reduce the annual holding costs by $€$ $283.5 \times 1000 €$.

In order to evaluate the impact of the changes considered, some additional costs must be taken into consideration. In particular, the introduction of transhipment policies means an investment cost of about $€ 180,000$, which is necessary to purchase the van, the software system and to train the personnel, an increase in the annual indirect costs of $€ 80,000$ and an increase of annual transport costs of $\epsilon 120,000$. The payback period for this To-Be model can be calculated as 2.35 years (considering a $5 \%$ rate of updating).

As the simulation model has been developed using average data of a healthcare system, these results can be useful to identify the optimal supply chain configuration, as a function of the operating conditions. Moreover, outcomes from this study provide some insights about the supply chain inventory components and their trend, depending on the considered configuration.

\section{References}

AbuKhousa, E., Al-Jaroodi, J., Lazarova-Molnar, S., \& Mohamed, N. (2014). Simulation and Modeling Efforts to Support Decision Making in Healthcare Supply Chain Management. The Scientific World Journal, Volume 2014, Article ID 354246, 16 pages. http://dx.doi.org/10.1155/2014/354246

Ana, V.P.R., Ivy, J.S., \& King, R.E. (2008). A simulation-based approach for inventory modeling of perishable pharmaceuticals. In Proceedings of the Winter Simulation Conference (WSC '08). 1532-1538.

Balaji, S., Lewis, O., \& Rai, A. (2010). RFID-enabled capabilities and their impact on healthcare process performance. Proceedings of the 17th European Conference on Information Systems.

Banerjee, A., Burton, J., \& Banerjee, S. (2003). A simulation study of lateral shipments in single supplier, multiple buyers supply chain networks. International Journal of Production Economics, 81-82, 103-114. ISSN: 0925-5273. http://dx.doi.org/10.1016/S0925-5273(02)00366-3

Behzad, B., Moraga, R.J., \& Chen, S.J. (2011). Modelling healthcare internal service supply chains for the analysis of medication delivery errors and amplification effects. Journal of Industrial Engineering and Management (JIEM), 4(4), 554-576. http://dx.doi.org/10.3926/jiem.201

Bertolini, M., Bevilacqua, M., Ciarapica, F.E., \& Giacchetta, G. (2011). Business Process Re-Engineering in Healthcare Management: a Case Study. Business Process Management Journal, 17(1), 42-66. http://dx.doi.org/10.1108/14637151111105571 
Bevilacqua, M., Ciarapica, F.E., Mazzuto, G., \& Paciarotti, C. (2013). The impact of RFID technology in hospital drug management: An economic and qualitative assessment. International Journal of RF Technologies: Research and Applications, 4(3-4), 181-208.

Bevilacqua, M., Ciarapica, F.E., \& Paciarotti, C. (2009). Safety management system in a clinical medicine department: A case study. IFAC Proceedings Volumes (IFAC-PapersOnline), 13 (Part 1), 292-297

Bishara, R.H. (2006). Cold chain management - an essential component of the global pharmaceutical supply chain. American Pharmaceutical Review, 9(1), 105-109.

Chan, F.T.S., \& Chan, H.K. (2005). Simulation modeling for comparative evaluation of supply chain management strategies. Journal of Advanced Manufacturing Technology, 25(9/10), 998-1006. http://dx.doi.org/10.1007/s00170-003-1920-7

Chiou, C.C. (2008). Transshipment Problems in Supply Chain Systems: Review and Extensions. Supply Chain, Theory and Applications. Vienna, Austria: I-Tech Education and Publishing. 558.

Chow, G., \& Heaver, T. (1994). Logistics in the Canadian health care industry. Canadian Logistics Journal, 1(1), 29-74.

Ciarapica, F.E., Giacchetta, G., \& Paciarotti, C. (2008). Facility management in the healthcare sector: Analysis of the Italian situation. Production Planning and Control, 19(4), 327-341. http://dx.doi.org/10.1080/09537280802034083

Gjerdrum, J., Jalisi, Q.W.Z., Papageorgiou, L.G., \& Shah, N. (2000). Dynamic simulation of physical and business processes for supply chain improvement. Proceedings of the 5th annual conference on industrial engineering theory, applications and practice. Hsinchu, Taiwan.

Haavik, S. (2000). Building a demand-driven, vendor-managed supply system. Healthcare Financial Management, 54(2), 56-61.

Haijema, R., van der Wal, J., \& van Dijk, N.M. (2007). Blood platelet production: optimization by dynamic programming and simulation. Computers \& Operations Research, 34(3), 760-779. http://dx.doi.org/10.1016/j.cor.2005.03.023

Harrison, M., \& Tatsuya, I. (2006). Improving the safety and security of the pharmaceutical supply chain. Learnings from the Drug Security Network. Auto-id Center, Massachusetts Institute of Technology, Cambridge, MA.

Ivan-Su, S.L., Gammelgaard, B., \& Yang, S.L. (2011). Logistics innovation process revisited: insights from a hospital case study. International Journal of Physical Distribution \& Logistics Management, 41(6), 577-600. http://dx.doi.org/10.1108/09600031111147826 
Jacobson, S.H., Sewell, E.C., Proano, R.A., \& Jokela, J.A. (2006). Stockpile levels for pediatric vaccines: how much is enough? Vaccine, 24(17), 3530-3537.

http://dx.doi.org/10.1016/j.vaccine.2006.02.004

Katsaliaki, K., \& Mustafee, N. (2011). Applications of simulation within the healthcare context. Journal of the Operational Research Society, 62(8), 1431-1451.

http://dx.doi.org/10.1057/jors.2010.20

Koh, R., Schuster, E.W., Chackrabarti, I., \& Bellman, A. (2003). Securing the Pharmaceutical Supply Chain. Cambridge, MA: Auto-id Center, Massachusetts Institute of Technology.

Kopach, R., Balcioğlu, B., \& Carter, M. (2008). Tutorial on constructing a red blood cell inventory management system with two demand rates. European Journal of Operational Research, 185(3), 1051-1059. http://dx.doi.org/10.1016/j.ejor.2006.01.051

Lapierre, S.D., \& Ruiz, A.B. (2007). Scheduling logistic activities to improve hospital supply systems. Computers \& Operations Research, 34(3), 624-641.

http://dx.doi.org/10.1016/j.cor.2005.03.017

Lee, S.M., Lee, D., \& Schniederjans, M.J. (2011). Supply chain innovation and organizational performance in the healthcare industry. International Journal of Operations \& Production Management, 31(11), 1193-1214. http://dx.doi.org/10.1108/01443571111178493

Lee, Y.H., Jung, J.W., \& Jeon, Y.S. (2007). An effective lateral transshipment policy to improve service level in the supply chain. International Journal of Production Economics, 106, 115-126. ISSN: 0925-5273.

Montgomery, D.C. (2008). Introduction to Statistical Quality Control. VI edition. John Wiley \& Sons Inc.

Naseer, A., Eldabi, T., Jahangirian, M., \& Stergioulas, L. (2008). Potential applications of simulation modelling techniques in healthcare: lessons learned from aerospace \& military. In Proceedings of the 5th European and Mediterranean Conference on Information Systems (EMCIS '08). Dubai, United Arab Emirates.

Ontario Buys, \& Health Care Supply Network (2007). Supply chain modernization in Ontario health care, improving patient care, enhancing service levels and reducing costs: a report on the e-supply chain project. Ontario Ministry of Finance. Toronto. Available at: http://www.hscn.org/Data/Sites/1/whitepapers/esupplychainreport final web eng.pdf

Rossetti, C.L., Handfield, R., \& Dooley, K.J. (2011). Forces, trends, and decisions in pharmaceutical supply chain management. International Journal of Physical Distribution \& Logistics Management, 41(6), 601-622. http://dx.doi.org/10.1108/09600031111147835 
Rytilä, J.S., \& Spens, K.M. (2006). Using simulation to increase efficiency in blood supply chains. Management Research News, 29(12), 801-819.

http://dx.doi.org/10.1108/01409170610717826

Sarac, A., Absi, N., \& Dauzère-Pérès, S. (2010). A literature review on the impact of RFID technologies on supply chain management. International Journal of Production Economics, 128(1), 77-95. http://dx.doi.org/10.1016/j.ijpe.2010.07.039

Sinha, K.K., \& Kohnke, E.J. (2009) Health Care Supply Chain Design: Toward Linking the Development and Delivery of Care Globally. Decision Sciences. 40(2), 197-212. http://dx.doi.org/10.1111/j.1540-5915.2009.00229.x

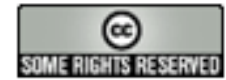

Article's contents are provided on an Attribution-Non Commercial 3.0 Creative commons license. Readers are allowed to copy, distribute and communicate article's contents, provided the author's and Journal of Industrial Engineering and Management's names are included. It must not be used for commercial purposes. To see the complete license contents, please visit http://creativecommons.org/licenses/by-nc/3.0/. 